\title{
AOR
}

Selected Papers of \#AolR2020:

The $21^{\text {st }}$ Annual Conference of the

Association of Internet Researchers

Virtual Event / 27-31 October 2020

\section{'DON'T CREATE AN ONLINE IMAGE THAT YOU CAN'T KEEP UP OUTSIDE': MEDIATING INVISIBLE COMMUNICATIVE DISABILITIES ON SOCIAL NETWORK SITES}

\author{
Nomy Bitman \\ Department of Communication and Journalism, The Hebrew University of Jerusalem
}

Internet use among disabled people has long been studied in the context of mediated communication, assistive technologies, social inclusion, and participation (Alper, 2017; Ellis \& Kent, 2011), with a focus on Social Network Sites (henceforth, SNS) (Alper \& Haller, 2017). Across these studies emerges a techno-optimist discourse, marked by a prevalent assumption that the internet is empowering and liberating for disabled people. This assumption is largely based on the user's lack of physical body online which ostensibly results in a split between material and online identities and presentations of self (Baym \& Markham, 2009; Turkle, 1995).

This assumption is problematic because it overlooks, perhaps due to a reproduction of ableist power relations, critical analyses of disability as a distinct identity category which suffers from social inequality (Goggin, 2017; Nakamura, 2002). This ableism is reflected in the perception of disability as a barrier to people's authentic expression offline, and a corresponding idealization of the internet as a conduit that enables users to 'leave the disability behind' (Bowker \& Tuffin, 2002). Ableism in this context implies that disability should be ignored, rather than serve as a natural component of one's online self. It has profound implications for the mediation of disability to able-bodied users.

This ongoing study addresses that gap by examining how disabled users mediate their lived experience on social media. Specifically, it explores the conscious, narrativebased decision-making process through which they create online personas. Since the exposure of disability on media can lead to stigmatization (Bitman \& John, 2019), I focus specifically on the understudied context of invisible disabilities that are clinically considered as related to communication. These types of disability can be potentially Suggested Citation (APA): Bitman, N. (2020, October). 'Don't create an online image that you can't keep up outside': Mediating invisible communicative disabilities on social network sites. Paper presented at AolR 2020: The 21 $1^{\text {th }}$ Annual Conference of the Association of Internet Researchers. Virtual event: AolR. Retrieved from http://spir.aoir.org. 
concealed offline, but they are especially "manageable" on visually-dominant SNS platforms, thus providing a fruitful perspective on how disabled individuals actively create an online self. Through a process of purposive sampling, I recruited 11 stutterers, 7 high-functioning autistics, and 11 hard of hearing individuals, all of whom have active SNS profiles, by contacting relevant national organizations, community leaders and past interviewees. I conducted 31 in-depth interviews and collected 7 diaries documenting interviewees' SNS use. Both interview transcripts and diaries were analyzed thematically.

Findings suggest that individuals' personal relationship with their disability indirectly shaped perceptions of their social environment and influenced how they performed their disabled identity online and offline. Thus, interviewees who related positively to their disability, both as an individual identity and as a membership in a community, often had a more diverse social environment online, that included both able-bodied and disabled friends. As a result, they expressed a more realistic, complex, and honest performance of disability. For example, such interviewees would post personal notes highlighting nuances of discrimination in their everyday lives. Conversely, interviewees who perceived disability as a hurdle in everyday interactions with able-bodied people, tended to avoid sharing their disability online due to a perception that SNS are mostly constituted by able-bodied people. The combination of personal discomfort and its projection on the digital social environment resulted in creating and maintaining online personas more akin to those of able-bodied users.

SNS Friends from 'the offline world' often made disabled users feel subjected to social surveillance. Rather than experiencing freedom from social stigmatization, many interviewees felt that they had to 'pass' as able-bodied communicators in their online expression. Stutterers are a case in point. Generally, stutterers tended to have an ambivalent relationship with the disability label, certainly more so than autistics and hard of hearing users. Falsely perceived as able to control speech disfluency (St. Pierre, 2013), the struggle of this group is often minimized. Since they face negative social feedback about their speech disfluency, many stutterers feel obliged to assume a quiet and introverted demeanor, which leads to frustration about their inability to express their true personality. Although the dominance of the written word makes SNS ostensibly accessible for stutterers, I found that "authenticity" posed a barrier. Interviewees described a pressure to align their online persona and communicative style with their offline one, forcing them to craft a more introverted version of themselves. As explained by Simon: "When your disability is invisible, you can be whoever you want in social media; whether it is the authentic you or just a posture. But at the same time, you know that when you're 'outside' you have to keep maintaining that posture, which may be impossible".

This authenticity barrier was intensified given a common recognition of SNS, Facebook in particular, as media environments that either idealize disabled life (as reflected in the 'supercrip' theme which highlights the extraordinary achievements and dispositions of disabled people) or victimize it (as reflected in the theme of the disabled person who unjustly 'pretends to be miserable'). Thus, users with an invisible communicative 
disability are faced with a double bind: The demand for authenticity limits their online persona to what people recognize as their physical attributes; at the same time, what is considered as 'authentic' by general SNSs' able-bodied users is informed by dichotomous representations that fail to reflect the complex lived experience of disability.

By considering the social and material aspects of social media platforms, and the communicative difficulties and opportunities stemming from online and offline visibility, this research challenges the still dominant binary of dis/abled bodies, and offers a fluid understanding of the performance of disability on SNS. Challenging prevailing conceptions of the internet as accessible, empowering and liberating, this study suggests that the mediation of lived experiences of disability is limited by ableist conceptions of the digital sphere. This research thus contributes to the theoretical understanding of disability performance on social media as part of a wider discussion on online identity construction.

\section{References}

Alper, M. (2017). Giving voice: Mobile communication, disability, and inequality. Cambridge, MA: MIT Press.

Alper, M., \& Haller, B. (2017). Social media use and mediated sociality among individuals with communication disabilities in the digital age. In Ellis, K., \& Kent, M. (Eds.), Disability and Social Media: Global Perspectives (pp. 133-145). New York, NY: Routledge.

Baym, N. K., \& Markham, A. N. (2009). Introduction: Making smart choices on shifting ground. In A. N. Markham \& N. K. Baym (Eds.). Internet Inquiry: Conversations about Method (pp. vii-xix). Thousand Oaks, CA: Sage.

Bowker, N., \& Tuffin, K. (2002). Disability discourses for online identities. Disability \& Society, 17(3), 327-344.

Bitman, N., \& John, N. A. (2019). Deaf and hard of hearing smartphone users: Intersectionality and the penetration of ableist communication norms. Journal of Computer-Mediated Communication, 24(2), 56-72.

Ellis, K., \& Kent, M. (2011). Disability and new media. New York, NY: Routledge.

Goggin, G. (2017). Disability and digital inequalities: Rethinking digital divides with disability theory. In M. Ragnedda \& G. W. Muschert (Eds.) Theorizing Digital Divides (pp. 69-80). London, UK: Routledge.

Nakamura, L. (2002). Cybertypes: Race, Ethnicity, and Identity on the Internet. New York, 
NY: Routledge.

Pierre, J. S. (2013). The construction of the disabled speaker: Locating stuttering in disability studies. In C. Eagle (ed.) Literature, Speech Disorders, and Disability: Talking Normal (pp. 17-31). New York, NY: Routledge.

Turkle, S. (1995). Life on the Screen: Identity in the Age of the Internet. New York, NY: Simon and Shuster. 